\title{
Uncemented Total Hip Replacement Stem Loosening after Long Term Compressive Stress Application: A Simulated FEA Study of Cortical Bone Remodeling*
}

\author{
Duk-Young JUNG ${ }^{* *}$, Sadami TSUTSUMI**, Ryusuke NAKAI**, \\ Ken IKEUCHI ${ }^{* * *}$ and Ron SEKEL****
}

\begin{abstract}
The purpose of this study is to predict with the use of FEA, the differing predisposition to cortical bone resorption and subsequent distal migration of an un-cemented femoral hip replacement stem subjected to long term biomechanical high compressive stresses, while varying the load angles, the material properties of the stem, and the stem length. A twodimensional hip model was constructed to estimate the minimum principle stresses $\left(P_{3}\right)$ and migration magnitudes. Bone remodeling at the interface between the bone and the prosthesis was performed by comparison of the local compressive stress to physiological stress values governing bone resorption. With respect to load angles, migrations of the hip prosthesis did not occur with load angles between $63^{\circ}$ and $74^{\circ}$ load angle in relation to the longitudinal axis of the bony femur, as the compressive stress generated on the cortical bone was under the criteria threshold for bone resorption $(-50 \mathrm{MPa})$. In addition, the magnitude of migration $(17 \%$ decrease) was relatively more sensitive to changes in stem length than those ( $92 \%$ decrease) of changes of material properties. In conclusion, using an FEA model for bone remodeling, based on the high compressive stresses exerted on distal cortical bone, it is possible to estimate migration magnitudes of cementless hip prostheses in the long term. The load angles have been shown to be an important parameter affecting the migration magnitudes and furthermore, it can be demonstrated that the stiffer materials and reduction of stem length can decrease the migration of cementless hip prosthesis in the long term.
\end{abstract}

Key Words: Migration, Hip Prosthesis, Bone Remodeling Simulation, High Compressive Stress

\section{Introduction}

The clinical loosening and the subsequence migration of hip replacement prosthesis stem within femur have played a major rule in determining the medium and long

* Received 24th May, 2004 (No. 04-4124)

** Department of Medical Simulation Engineering, Research Center for Nano Medical Engineering, Institute for Frontier Medical Sciences, Kyoto University, 53 Kawaharacho, Shogoin, Sakyo-ku, Kyoto 606-8507, Japan.

E-mail: Jung@frontier.kyoto-u.ac.jp

*** Department of Nano Biomechanism, Research Center for Nano Medical Engineering, Institute for Frontier Medical Sciences, Kyoto University, 53 Kawahara-cho, Shogoin, Sakyo-ku, Kyoto 606-8507, Japan.

E-mail: Ikeuchi@frontier.kyoto-u.ac.jp

**** Department of Orthopaedics, St. George Hospital, University of New South Wales, Sydney 2217, Australia.

E-mail: Ronsekel@margron.com term success of implant designs ${ }^{(1)-(6)}$. Many studies have investigated the causes through both experimental and numerical approaches ${ }^{(7)-(14)}$. Numerous biomechanical studies have verified that the inserted prosthesis changes the natural stress patterns in cortical and cancellous bone, and that the bone is absorbed or reformed to adapt to the changed stresses around the implanted prosthesis. Sugiura et al. ${ }^{(15)}$ reported that the critical threshold of compressive stress for cortical bone resorption was around $-50 \mathrm{MPa}$ (3600 $\mu$ strain) using mechanical testing and in vivo studies on the mini-plates.

Several stress or strain-related adaptive mechanisms for bone resorption were proposed to estimate the loosening of prostheses in the literature ${ }^{(16)-(21)}$. Weinans et al. ${ }^{(19)}$ simulated the bone remodeling process based on the stress level after inserting different kinds of implants. They showed that loosening and micro-motion between an implant and bone occurred in the high compressive stress 
regions when they rose above the threshold stress values sufficient to cause bone resorption. However, there were no considerations of the various biomechanical parameters effecting bone remodeling in the long term.

In hip replacement, the concentrated high compressive stress around the distal region of the cementless stem after implantation can be more easily contributed to the micro-motion and secondary osteolysis which then leads to bone resorption and the stem migration in the long term $^{(1),(3)}$. Even thought there were several biomechanical studies estimating the migration of hip prosthesis with initial strain or stress analyses ${ }^{(11),(14)}$, many clinical studies showed that loosening and subsequence migration occurred in the very long term, after 5-10 years $^{(1),(2)}$. In addition, the mechanism of bone remodeling after a cementless hip implantation is very complex and there is still much controversy over the mechanical and designing parameters governing the loosening and subsequence migration of a cementless hip prosthesis.

The purpose of this study was to simulate the cortical bone resorption phenomena due to the concentrated high compressive stresses around the inserted cementless hip prosthesis, and to predict the amount of migration of hip replacement stems in the long term subject to differing biomechanical load angles, material properties and stem designs.

\section{Methods}

\subsection{Cortical bone remodeling based on the local compressive stress}

In this study it was hypothesized when the relative compressive stress on bone was higher than a certain criteria threshold, that this was responsible for cortical bone resorption at the interface between the implant and bone. It was also assumed that the loosening starts with the microdisruption of the cortical bone between a well-fixed implant and surrounding bone, because of the repetitive excessive interface loading. The migration of prosthesis was then progressive, with stem-migration into the absorbed regions in the long term.

A hypothetical scheme of bone remodeling process based on the compressive stress for the cortical bone resorption is shown in Fig. 1. After hip implantation, the minimum principle stress $\left(P_{3}\right)$ was evaluated in the local points of cortical bone using finite element analysis (FEM), and then the local compressive stress values $\left(S_{i}\right)$ were compared to the criteria threshold of compressive stress $\left(S_{c}\right)$ for determining the reduction ratio $\left(R_{i}\right)$ of the cortical bone. The reduction ratio $\left(R_{i}\right)$ was derived by the hypothetic equation governing not only the quantity of bone remodeling but also absorption direction as shown in Fig. 2. When the $P_{3}$ stress $\left(S_{i}\right)$ was over the criteria threshold value $\left(S_{c}\right)$ in local cortical bone, the bone was absorbed around the implant. If the $P_{3}$ stress $\left(S_{i}\right)$ was

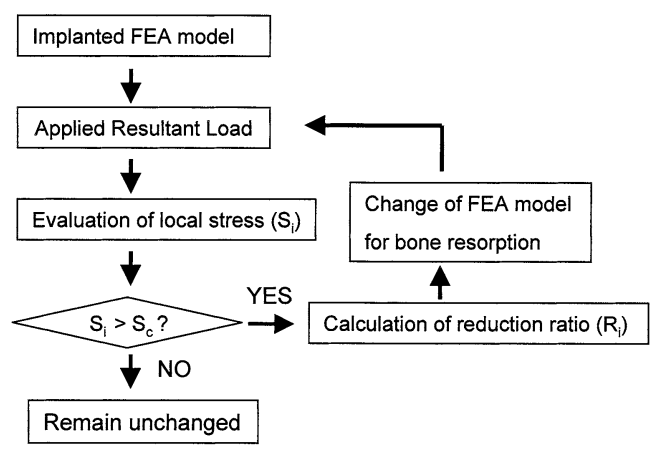

Fig. 1 Hypothetical scheme of the cortical bone remodeling process based on the local compressive stress $\left(S_{i}\right)$ and criteria threshold of compressive stress $\left(S_{c}\right)$ around hip prosthesis

$$
R_{i}=\left[\begin{array}{cll}
-\mathrm{C}_{\mathrm{a}} \operatorname{Ln}\left(\frac{\mathrm{S}_{\mathrm{i}}}{2 \mathrm{t} * \mathrm{Sc}}\right)-4 \mathrm{C}_{\mathrm{b}} \text {, when } 2 \mathrm{t} * \mid \mathrm{Sd}< & \left|\mathrm{S}_{\mathrm{i}}\right| \\
-\mathrm{C}_{\mathrm{a}}\left(\frac{\mathrm{S}_{\mathrm{i}}}{\mathrm{t}^{*} \mathrm{Sc}}\right)^{2} & \text {, when } & \mathrm{t} *\left|\mathrm{~S}_{\mathrm{c}}\right|<\left|\mathrm{S}_{\mathrm{i}}\right| \leq 2 \mathrm{t} *\left|\mathrm{~S}_{\mathrm{c}}\right| \\
0 & \text {, when } & \left|\mathrm{S}_{\mathrm{i}}\right| \leq \mathrm{t} *\left|\mathrm{~S}_{\mathrm{c}}\right|
\end{array}\right]
$$

$R_{i}$ : Reduction ratio for bone absorption

$S_{i}$ : Local compressive stress at $i$-th node

$S_{c}$ : Criteria threshold of compressive stress

$t \quad$ : constant parameter for Lazy zone

$C_{a}, C_{b}$ : constant parameters for remodeling velocity

Fig. 2 Hypothetic relation equations between element change and local compressive stress

below the critical threshold $\left(\mathrm{S}_{c}\right)$ then the shape of cortical bone remained unchanged. In this study the criteria threshold value of compressive stress $\left(S_{c}\right)$ was $-50 \mathrm{MPa}$ based on the literature ${ }^{(15)}$. The lazy zone was determined by the $t$ parameter for remodeling process ${ }^{(18)}$, and $C_{a}$ and $C_{b}$ were proportional constants for remodeling velocity (Fig. 2). Since values for these constants were, as yet, unknown, they were given as arbitrary values. The simulation process was repeated until it was unstabilized when proliferation to clinical migration was evident up to the maximum 10 cycles.

\subsection{FEM model for cortical bone remodeling}

For the cortical bone remodeling around the cementless hip prosthesis, two-dimensional hip models were constructed with isotropic, elastic and four-node elements. The cementless hip stem prosthesis was then implanted in accordance with a standard surgical method as illustrated in Fig. 3. It was assumed that the interface between the hip implant and the bone was rigidly fixed in this simulation. The most distal nodes in the diaphysis were fixed in all direction for boundary conditions, and a joint reaction resultant force of $510 \mathrm{~N}$ was applied to a $28 \mathrm{~mm}$ diameter femoral head with an elastic modulus of $410 \mathrm{GPa}$.

Figure 3 illustrates the three major parameters for cor- 


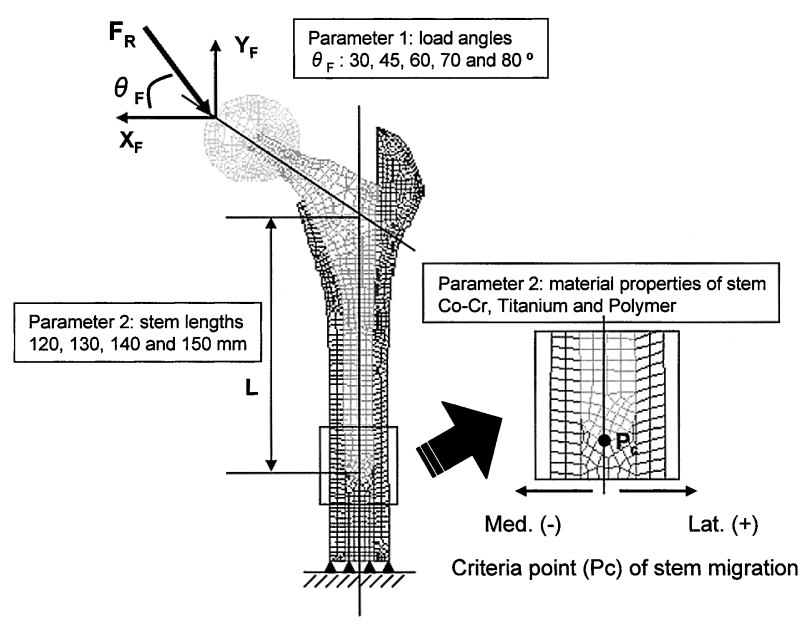

Fig. 3 Computational simulation hip model and mechanical major three parameters for the cortical bone remodeling $\left(F_{R}=510 \mathrm{~N}, L\right.$ : Stem Length, Med.: Medial side, Lat.: Lateral side)

Table 1 The material properties assigned to the hip FEM model

\begin{tabular}{cccc}
\hline \multirow{2}{*}{ Component } & $\begin{array}{c}\text { Material } \\
\text { Type }\end{array}$ & $\begin{array}{c}\text { Elastic } \\
\text { Modulus } \\
(\mathrm{MPa})\end{array}$ & $\begin{array}{c}\text { Poisson } \\
\text { Ratio } \\
(\nu)\end{array}$ \\
\hline \multirow{3}{*}{ Bone } & Cortical & 17,000 & 0.3 \\
\cline { 2 - 4 } & Cancellous & 300 & 0.3 \\
\hline \multirow{3}{*}{ Femoral Stem } & Polymer & 17,000 & 0.45 \\
\cline { 2 - 4 } & Titanium & 110,000 & 0.3 \\
\cline { 2 - 4 } & Co-Cr & 210,000 & 0.3 \\
\hline Femoral Head & Ceramic & 410,000 & 0.21 \\
\hline
\end{tabular}

tical bone remodeling and the criteria point $\left(P_{c}\right)$ on the end of the stem. The migration quantities of the hip prosthesis were calculated on $P_{c}$ after the end of the bone remodeling process. The first parameter, the loading direction was ranged from $30^{\circ}$ to $80^{\circ}$ as this was considered to be typical of daily activity ${ }^{(22)-(24)}$. The second parameter was the material properties (Cobalt-Chrome, Titanium and Polymer) usually used in hip prosthesis. The last parameter, stem lengths $(L)$ was considered as the designing factor. In the Table 1, the cortical and cancellous bones were assigned with elastic modulus of $17 \mathrm{GPa}$ and $300 \mathrm{MPa}$ each other. A Poisson's ratio of 0.3 was used for both the cortical and the cancellous bone. The thickness of cortical bone was about $1.5 \mathrm{~mm}$, and the implanted hip prosthesis was simulated with width of $15 \mathrm{~mm}$ and femoral neck angle of $135^{\circ}$. All stress analyses were carried out as a plane stress problem with COSMOS/M ver. 2.5 (SRAC, USA) under the same loading quantity and boundary condition. The computer program to evaluate the changes in modulus and geometry of cortical bone based on a change in reduction ratio $\left(R_{i}\right)$ was developed by FORTRAN and combined with the FEM codes.

\section{Results}

\subsection{Cortical bone resorption around hip prosthesis}

On the cementless hip prosthesis, stress analyses showed that the peak compressive stress occurred in the lateral distal cortical bone around the hip prosthesis except for the $80^{\circ}$ load angle, which was a typical patterns for a stem inserted in uncemented mode. At the distal lateral interface the loosening and subsequence migration of the hip prosthesis commenced, and the distal end of prosthesis then moved into lateral cortical bone as shown in Fig. 4 (a) - (a)', (c). The computational simulation of cortical bone remodeling results was well in agreement with the clinical following data in the long term such as endosteal scalloping migration (Fig. 4(b) - (b)') as clinically reported $^{(1),(2),(6)}$.

\subsection{Comparison of migration quantities in relation to changes in loading angles}

Figure 5 shows the peak compressive stresses $\left(P_{3}\right)$ at the distal cortical bone and the migration quantities of the distal stem in relation to changes in load angles ranged from $30^{\circ}$ to $80^{\circ}$. In the distal lateral cortical region, the peak compressive stress decreased with increasing load angles, and the stress values was lower than the criteria threshold of compressive stress $\left(S_{c}\right)$ over $63^{\circ}$ load angle. In contrast, the peak compressive stress value exceeded the criteria value at $74^{\circ}$ load angle in the distal medial regions as shown Fig. 5 (a).

It was noted that migration decreased up to $63^{\circ}$ load angle along with the decrease of peak compressive stress toward the distal lateral cortical bone, and increased again from $74^{\circ}$ load angle facing distal medial cortical bone. Therefore, it was found that the migration of hip prosthesis did not occur with load angles from $63^{\circ}$ to $74^{\circ}$ load angle, as the compressive stress on bone was under the criteria threshold of compressive stress $(-50 \mathrm{MPa})$ governing cortical bone resorption as shown Fig. 5 (b).

\subsection{Respective migration changed with material properties of stem}

With respect to the material properties, the high stiffness hip prosthesis exerted higher compressive stresses than those of lower stiffness on the distal medial cortical bone. In cobalt-chrome alloy with the higher stiffness, the migration quantity on the distal region after 10 cycles was lowest compared to other materials as shown in Fig. 6. The polymer prosthesis, having a similar material property to that cortical bone, had the highest migration of almost $8 \%$ more than titanium, and $17 \%$ more than cobalt-chrome alloy stems. These results suggest, for given design that the use of stiffer material is able to decrease the failure possibility of a cementless hip prosthesis in the long term.

\subsection{Comparison of migration changed with stem length}

The magnitudes of migration were relatively more 


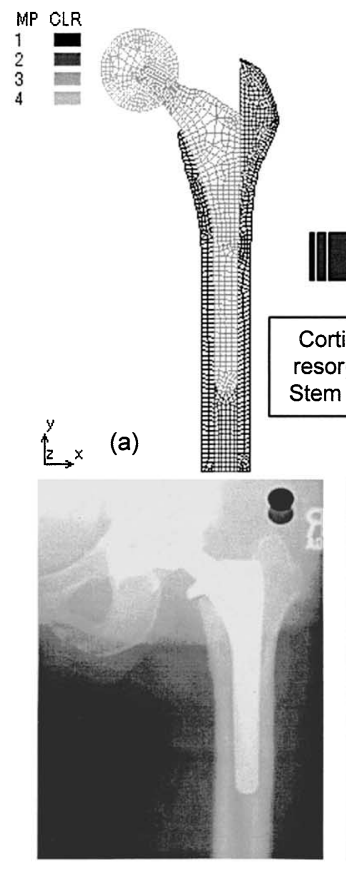

(b)

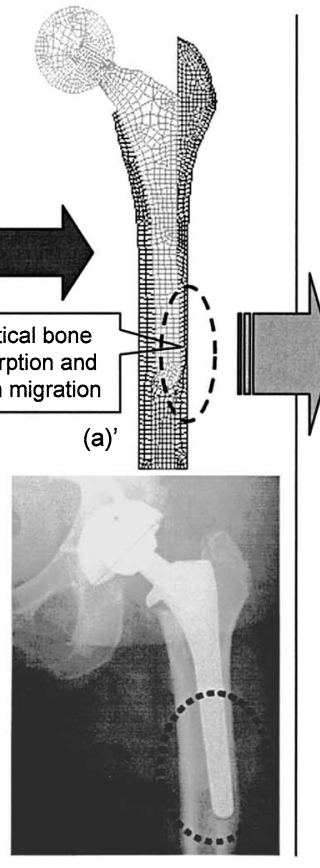

(b)'

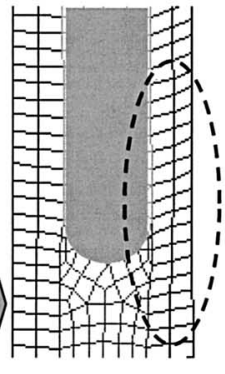

2 cycles

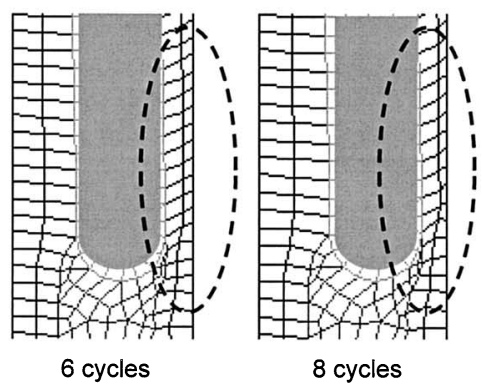

(c)

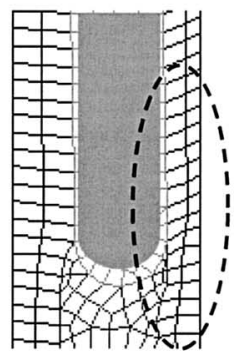

4 cycles

Fig. 4 Comparison of the cortical bone resorption (a), (a)' and stem migration (c) to clinical 5-year follow-up data (b), (b)' under $45^{\circ}$ load angle and stem length of $150 \mathrm{~mm}$ on the cementless hip prosthesis (dot circle region: bone resorption and stem migration)

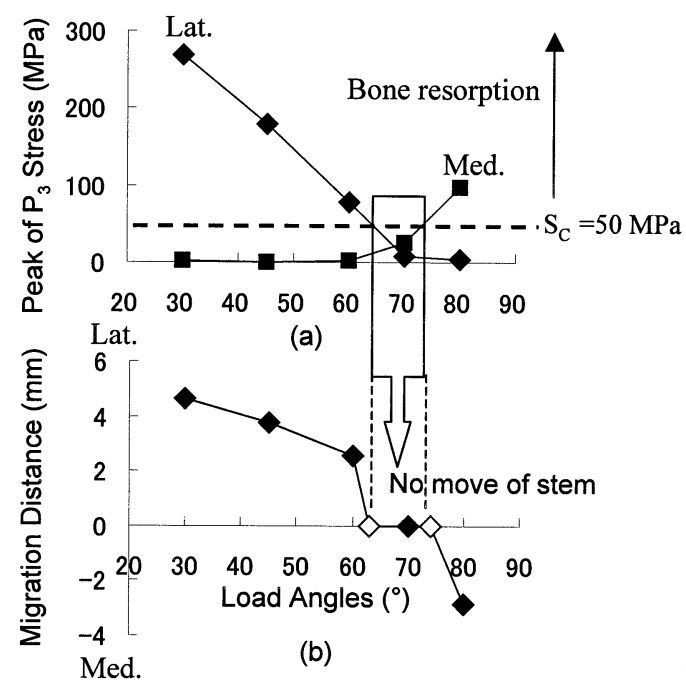

Fig. 5 Comparison of local compressive stresses and migration quantities in relation to changes in load angles (Med.: Medial side, Lat.: Lateral side, $S_{c}$ : Criteria threshold of compressive stress)

sensitive to changes in stem length than those of changes in material properties of cementless hip prosthesis. Decreasing the length of the femoral stem caused a decrease in the peak compressive stress within the distal lateral cortical bone, and a decrease in the predicted migration quantities into the distal lateral cortical bone. Figure 7 shows that the decrease of stem length from $150 \mathrm{~mm}$ to $120 \mathrm{~mm}$ resulted in $26 \%$ decrease of the predicted peak compres-

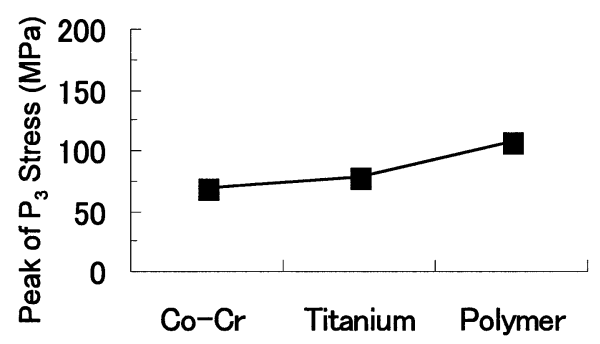

(a)

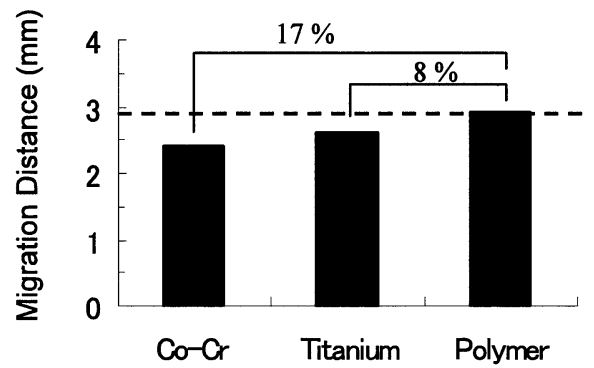

(b)

Fig. 6 Comparison of compressive stresses and migration quantities in relation to changes in material properties (Co-Cr: $E=220 \mathrm{GPa}$, Titanium: $E=110 \mathrm{GPa}$, Polymer: $E=17 \mathrm{GPa}$ ) under $45^{\circ}$ load angle and stem length of $150 \mathrm{~mm}$

sive stress in the cortical bone, and a $92 \%$ decrease of the predicted migration quantities of the distal end of the cementless hip prosthesis. The decreasing trend of migration quantities was exponentially related to changes in the stem lengths in the present study as shown in Fig. 7 (b). 


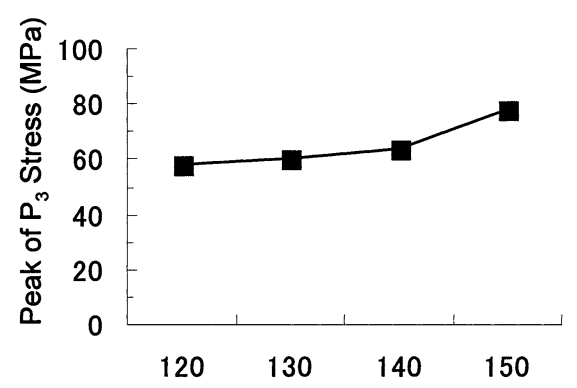

(a)

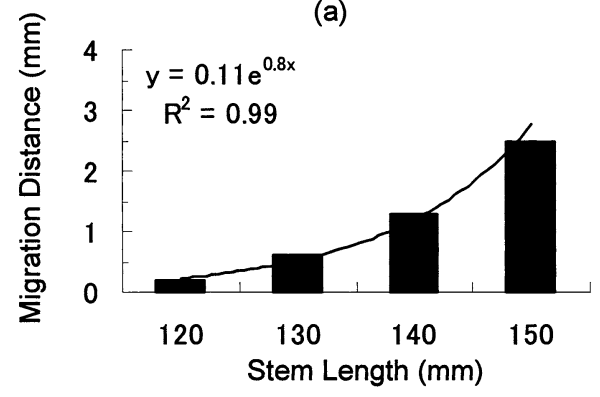

(b)

Fig. 7 Comparison of compressive stresses and migration quantities in relation to changes in stem lengths $(L)$ under $45^{\circ}$ load angle and titanium stem

\section{Discussion}

This study was focused on simulating the clinical loosening and the subsequence migration of a cementless hip prosthesis based on the generation of high compressive stress around distal cortical bone, and estimating the migration quantities of the hip prosthesis using cortical bone remodeling FEA simulation methods in the long term.

Several simulation methods based on local stress- or strain for bone remodeling have been proposed in the literature to estimate the loosening phenomena between bone and prosthesis ${ }^{(18)-(20)}$. These simulation methods were performed with certain criteria threshold value of strainor stress values in bones. However, it has been generally known that there is no absolute value of the physiological strain- or stress governing bone resorption or deformation, because the physiological responses of bones varies in accordance with different bone constructs and load bearing during daily activity. Previous researchers reported that normal peak physiological strains governing load-bearing in adult bones were about $3000 \mu$ strain in tension and $4000 \mu$ strain in compression ${ }^{(15),(22),(25)}$. In our study, we applied the criteria threshold of compressive stress $(-50 \mathrm{MPa})$ as proposed by Sugiura et al. ${ }^{(15)}$ They reported that cortical bone resorption occurred in concentrated high compressive stress regions that were over the critical threshold value, which was about $3600 \mu$ stain (-50 MPa), shown with experimental testing and FEM analyses around mandibular screws. The concept based on the compressive stress for bone resorption also was reported by Huiskes et al. ${ }^{(18)}$ and Weinans et al. ${ }^{(19)}$ in detail.
For the cortical bone remodeling simulation, we assumed that the interface between cortical bone and the cementless hip prosthesis was fixed perfectly, and that loosening starts with the micro-disruption of the cortical bone between a well-fixed implant and the surrounding bone $^{(1),(4)}$. The present findings showed clearly that the concentrated high compressive stress $\left(P_{3}\right)$ dramatically lead to the loosening and the subsequence migration of cementless hip prosthesis. However, there were simulation limitations in our cortical bone remodeling method. Several clinical follow-up studies have shown that osteolysis may take place between the bone and prosthesis, even though the gaps filled with osseous ingrowth in the long term ${ }^{(1)}$. In future work, the gap element will need to be considered to over come the simulation limitation in this study. And the two-dimensional (2D) structure is inherently less stiff than a three-dimensional (3D) model, however, the periprosthesis stress distributions and levels predicted by our 2D model should be at least qualitatively consistent with those obtain in 3D analysis.

Our simulation results of the bone resorption phenomena in response to the stress level/distribution as well as bone morphology in the long term after total hip arthroplasty showed good agreement with clinical follow-up data explained below;

Throughout this study, the peak compressive stress was found to be present in the distal lateral cortical bone, and the distal migration quantities ranged from $0.2 \mathrm{~mm}$ to $4.6 \mathrm{~mm}$ at the interface. Emerson et al. ${ }^{(4)}$ reported that 7 femora $(8.9 \%)$ of 78 cementless stems in the distal regions had osteolysis compared with 22 femora $(21.5 \%)$ out of 102 cemented stems in all interfaces during the 2year follow-up. Nelissen et al. ${ }^{(5)}$ show the migration was present along the transverse $(-1.7 \pm 1.67 \mathrm{~mm})$ and sagittal $(1.1 \pm 2.95 \mathrm{~mm})$ axes with 2-year follow-up data. It was difficult to directly compare our migration quantities to the clinical data available in the literature, because of the different types of hip prosthesis described, and the shorter follow-up data. However, in our results, the pattern of compressive stress as well as migration directions in distal cortical bone are similar to those reported by the clinical data $^{(1),(2)}$ and other biomechanical studies ${ }^{(7),(10),(14)}$ as shown Fig. 4.

It was interesting to observe that the peak compressive stresses in distal cortical bone were under the criteria threshold of compressive stress in the range of $63^{\circ}-74^{\circ}$ load angles. Respectively, the migration of cementless hip prosthesis did not take place in the range as shown Fig. 5 (b). When considering loading history, these results show that the stress generated by a prosthesis, sufficient to cause migration of hip prosthesis can occur during adduction to about $34^{\circ}$ horizontal to the sagittal plane more than during the one-leg standing phase, at about $66^{\circ}$ horizontal to the sagittal plane ${ }^{(20),(24)}$. It was also found that the 
range, where the migration was not occurred, was a little bit flexible in relation to changes of the threshold compressive stress was not absolute value (Fig. 5).

It is clear from previous experimental studies that stem stiffness has effects on the stability of total hip arthroplasty (THA) ${ }^{(26),(27)}$. With respect to material properties of hip prosthesis, our findings showed that the migration quantity of the lower stiffness hip prosthesis was $17 \%$ higher than that of higher stiffer prosthesis (Fig. 6). In other words, it is likely that a reduced stiffness stem can accelerate distal bone resorption because of enhanced distal load transfer from the hip prosthesis to the host bone. It was also estimated that using stiffer material is able to decrease the migrating possibility on a cementless hip prosthesis in the long term.

The magnitudes of migration were relatively more sensitive to changes in stem length than those of changes in material properties on cementless hip prosthesis. The migration quantities on the distal end of hip prostheses hardly increased with increasing the stem length from $120 \mathrm{~mm}$ to $150 \mathrm{~mm}$ (Fig. 7) compared with the changes in material changes. This result suggests that the use of long stem is able to cause increase in stem migration into the distal cortical bone. This increase of migration probably is related to the increase of bending moment arm when applying body weight to the femoral head.

In conclusion: the FEA bone remodeling method based on the high compressive stress around the distal end of cementless hip prosthesis probably can estimate the loosening and the subsequence migration in the long term. The load angles due to daily activity were identified be an important parameter, having an affect on the migration magnitudes as well as directions. In addition, it is considered that stiffer materials and reduction of stem length can decrease the migration of cementless hip prosthesis in the long term.

\section{Acknowledgements}

This investigation was supported in part by NEDO (New Energy and Industrial Technology Development Organization) and COE program of the Ministry of Education, Culture, Sports, Science and Technology, Japan.

\section{References}

( 1 ) Goetz, D.D., Smith, E.J. and Harris, W.H., The Prevalence of Femoral Osteolysis Associated with Components Inserted with or without Cement in Total Hip Replacements, J. Bone and Joint Surgery, Vol.76-A, No.8 (1994), pp.1121-1128.

( 2 ) Engartner, C., Volkman, R., Winter, E., Maurer, F., Sauer, G., Weller, S. and Weise, K., Results of an Uncemented Straight Femoral Shaft Prosthesis after 9 Years of Follow-up, J. Arthroplasty, Vol.15, No.4 (2000), pp.440-447.

( 3 ) Alfaro-Adrián, J., Gill, H.S. and Murray, D.W., Should
Total Hip Arthroplasty Femoral Components Be Designed to Subside? A Radiostereometric Analysis Study of the Charnly Elite and Exeter Stems, J. Arthroplasty, Vol.16, No.5 (2001), pp.598-606.

( 4 ) Emerson, R.H., Head, W.C., Emerson, C.B., Rosenfeldt, W. and Higgins, L.L., A Comparison of Cemented and Cementless Titanium Femoral Components Used for Primary Total Hip Arthroplasty: A Radiographic and Survivorship Study, J. Arthroplasty, Vol.17, No.5 (2002), pp.584-591.

( 5 ) Nelissen, R.G.H.H., Valstar, E.R., Pöll, R.G., Garling, E.H. and Brand, R., Factor Associated with Excessive Migration in Bone Impaction Hip Revision Surgery A Radiostereometric Analysis Study, J. Arthroplasty, Vol.17, No.7 (2002), pp.826-833.

( 6 ) Keogh, C.F., Munk, P.L., Gee, R., Chan, L.P. and Marchinkow, L.O., Imaging of the Painful Hip Arthroplasty, Am. J. Roentgenol, Vol.180, No.1 (2003), pp.115-120.

( 7 ) Bühler, D.W., Berlemann, U., Lippuner, K., Jaeger, J. and Nolte, L.P., Three-Dimensional Primary Stability of Cementless Femoral Stems, Clinical Biomechanics, Vol.12, No.2 (1997), pp.75-86.

( 8 ) Maher, S.A., Prendergast, P.J. and Lyons, C.G., Measurement of the Migration of a Cemented Hip Prosthesis in an in Vitro Test, Clinical Biomechanics, Vol.16 (2001), pp.307-314.

(9) Soltez, U., Siegele, D., Riedmuler, J. and Schulz, P., Stress Concentration and Bone Resorption in the Jaw for Dental Implant with Shoulders, Clinical Applications of Biomaterial, Edited by Lee, A.J.C., Alberksson, T., Branemark, P.-I., (1982), pp.115-123, John Wiley \& Sons, Chichester.

(10) Rubin, P.J., Rakotomanana, R.L., Leyvraz, P.F., Zysset, P.K., Curnier, A. and Heegaard, J.H., Frictional Interface Micromotions and Anisotropic Stress Distribution in a Femoral Total Hip Component, J. Biomechanics, Vol.26, No.6 (1993), pp.725-739.

(11) Keaveny, T.M. and Bartel, D.L., Effects of Porous Coating, with and without Collar Support, on Early Relative Motion for a Cementless Hip Prosthesis, J. Biomechanics, Vol.26, No.12 (1993), pp.1355-1368.

(12) Taylor, M., Tanner, K.E., Freeman, M.A.R. and Yettran, A.L., Cancellous Bone Stress Surrounding the Femoral Component of a Hip Prosthesis: An ElasticPlastic Finite Element Analysis, Med. Eng. Phys., Vol.17, No.7 (1995), pp.544-550.

(13) Gillies, R.M., Morberg, P.H., Bruce, W.J.M., Turnbull, A. and Walsh, W.R., The Influence of Design Parameters on Cortical Strain Distribution of a Cementless Titanium Femoral Stem, Medical Engineering \& Physics, Vol.24 (2002), pp.109-114.

(14) Pancanti, A., Bernakiewicz, M. and Viceconti, M., The Primary Stability of a Cementless Stem Varies between Subjects as much as between Activities, J. Biomechanics, Vol.36 (2003), pp.777-785.

(15) Sugiura, T., Horiuchi, K., Sugimura, M. and Tsutsumi, S., Evaluation of Threshold Stress for Bone Resorption around Screws Based on in Vivo Strain Measurement of Miniplate, J. Musculoskel Neuron Interact, Vol.1, 
No.2 (2000), pp.165-170.

(16) Cowin, S.C., Bone Remodeling of Diaphyseal Surfaces by Torsional Loads: Theoretical Predictions, J. Biomechanics, Vol.20, No.11/12 (1987), pp.1111-1120.

(17) Cheal, E.J., Synder, B.D., Nunamaker, D.M. and Hayes, W.C., Trabecular Bone Remodeling around Smooth and Porous Implants in Equine Patellar Model, J. Biomechanics, Vol.20, No.11/12 (1987), pp.11211134.

(18) Huiskes, R., Weinans, H., Grootenboer, H.J., Dalstra, M., Fudala, B. and Slooff, T.J., Adaptive BoneRemodeling Theory Applied to Prosthetic-Design Analysis, J. Biomechanics, Vol.20, No.11/12 (1987), pp.1135-1150.

(19) Weinans, H., Huiskes, R. and Grootenboer, H.J., Quantitative Analysis of Bone Reactions to Relative Motions at Implant-Bone Interfaces, J. Biomechanics, Vol.26, No.11 (1993), pp.1271-1281.

(20) Adachi, T., Tomita, Y., Sakaue, H. and Tanaka, M., Simulation of Trabecular Surface Remodeling Based on Local Stress Nonuniformity, JSME Int. J., Ser. C, Vol.40, No.4 (1997), pp.782-792.

(21) McNamara, B.P., Taylor, D. and Prendergast, P.J., Computer Prediction of Adaptive Bone Remodeling around Noncemented Femoral Prostheses: The Relationship between Damage-Based and Strain-Based Algorithms, Med. Eng. Phys., Vol.19, No.5 (1997), pp.1350-4533.
(22) Simões, J.A., Vaz, M.A., Blatcher, S. and Taylor, M., Influence of Head Constraint and Muscle Forces on the Strain Distribution within the Intact Femur, Medical Engineering \& Physics, Vol.22 (2000), pp.453-459.

(23) Ipavec, M., Brand, R.A, Pedersen, D.R., Mavčič, B., Kralj-Iglič, V. and Iglič, A., Mathematical Modeling of Stress in the Hip during Gait, J. Biomechanics, Vol.32 (1999), pp.1229-1235.

(24) Bergmann, G., Graichen, F. and Rohlmann, A., Hip Joint Loading during Walking and Running Measured in Two Patients, J. Biomechanics, Vol.26, No.8 (1993), pp.969-990.

(25) Brown, C.U., Kish, V.L., Norman, T.L., Gruen, T.A. and Blaha, J.D., Circumference Creep of Human Cortical Bone Suggests Threshold for Press-Fit Stem, ORS 47th Annual Meeting, February, (2001).

(26) Sumner, D.R., Turner, T.M., Igloria, R., Urban, R.M. and Galante, J.O., Functional Adaptation and Ingrowth of Bone Vary as a Function of Hip Implant Stiffness, J. Biomechanics, Vol.31 (1998), pp.909-917.

(27) Turner, T.M., Sumner, D.R., Urban, R.M., Igloria, R. and Galante, J.O., Maintenance of Proximal Cortical Bone with Use of a Less Stiff Femoral Component in Hemiarthroplastic of the Hip without Cement. An Investigation in a Canine Model at Six Months and Two Years, J. Bone Joint Surg. [Am], Vol.79-A (1997), pp.1381-1390. 